\title{
Clipping versus coiling for aneurysmal subarachnoid hemorrhage: a systematic review and meta-analysis of prospective studies
}

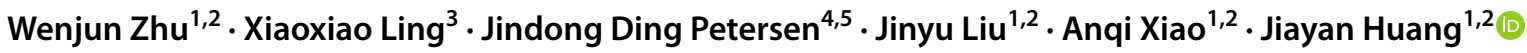

Received: 8 October 2021 / Revised: 7 November 2021 / Accepted: 24 November 2021 / Published online: 6 December 2021

(c) The Author(s) 2021

\begin{abstract}
Neurosurgical clipping and endovascular coiling are both standard therapies to prevent rebleeding after aneurysmal subarachnoid hemorrhage (aSAH). However, controversy still exists about which is the optimal treatment. This meta-analysis aims to assess the effectiveness and safety of two treatments with high-quality evidence. Web of Science, Cochrane Library, EMBASE, Pubmed, Sinomed, China National Knowledge Infrastructure, and Wanfang Data databases were systematically searched on August 5, 2021. Randomized controlled trials (RCTs) and prospective cohort studies that evaluated the effectiveness and safety of clipping versus coiling in aSAH patients at discharge or within 1-year follow-up period were eligible. No restriction was set on the publication date. Meta-analyses were conducted to calculate the pooled estimates and 95\% confidence intervals (CI) of relative risk (RR). Eight RCTs and 20 prospective cohort studies were identified. Compared to coiling, clipping was associated with a lower rebleeding rate at discharge (RR: 0.52, 95\% CI: 0.29--0.94) and a higher aneurysmal occlusion rate (RR: 1.33,95\% CI: 1.19-1.48) at 1-year follow-up. In contrast, coiling reduced the vasospasm rate at discharge (RR: 1.45, 95\% CI: 1.23-1.71) and 1-year poor outcome rate (RR: 1.27, 95\% CI: 1.16-1.39). Subgroup analyses presented that among patients with a poor neurological condition at admission, no statistically significant outcome difference existed between the two treatments. The overall prognosis was better among patients who received coiling, but this advantage was not significant among patients with a poor neurological condition at admission. Therefore, the selection of treatment modality for aSAH patients should be considered comprehensively.
\end{abstract}

Keywords Aneurysmal subarachnoid hemorrhage $\cdot$ Neurosurgical clipping $\cdot$ Endovascular coiling $\cdot$ Effectiveness $\cdot$ Safety Meta-analysis

Jiayan Huang

jiayanhuang@fudan.edu.cn

1 School of Public Health, Fudan University, Shanghai 200433, China

2 Key Lab of Health Technology Assessment, National Health Commission of the People's Republic of China, Shanghai 200433, China

3 Department of Statistical Science, University College London, London WC1E 6BT, UK

4 Department of Clinical Epidemiology, Department of Clinical Medicine, Aarhus University, Aarhus, Denmark

5 Research Unit for General Practice, Department of Public Health, University of Copenhagen, Copenhagen, Denmark

\section{Introduction}

Intracranial aneurysm (IA) is a cerebrovascular disorder in which the weakness of a cerebral artery wall causes a localized dilation of the blood vessel. IA can develop and rupture, and about $85 \%$ of spontaneous subarachnoid hemorrhage (SAH) cases are caused by the rupture of IA [35]. The attack rate of SAH varied across countries. The estimated incidence was 19.7 and 22.7 per 100,000 person-year in high incidence regions-Finland and Japan, while in other regions the overall rate was 9.1 per 100,000 person-year [9].

The prognosis of aneurysmal SAH is poor. Acute hydrocephalus occurred among around $15-20 \%$ of IA patients, which could cause intense headaches [18]. Cerebral vasospasm can also appear within 3 to 12 days after SAH [5], which may lead to ischemic cerebral infarction and even death. Rebleeding is another major cause of death. Without invasive therapy, the cumulative rebleeding rate would 
reach approximately $19 \%$ over the ensuing 2 weeks [24]. Moreover, $10-20 \%$ of patients would have a severe disability, and one-third of them would die because of SAH [21].

To prevent the rebleeding and improve the capacity for independent living of patients, effective interventions are required. Two treatments are available globally: neurosurgical clipping and endovascular coiling. Clipping is a method that requires craniotomy under general anesthesia. Permanent clips are placed across the neck of the aneurysm to exclude the aneurysm from circulation [5]. Coiling is performed under the angiographic techniques. Detachable coils of different shapes and sizes are deposited into the aneurysm through a microcatheter, which reduces the blood flow and induces thrombus formation [33]. There is a lot of controversy on which of these two methods is optimal. Compared to coiling, clipping has better durability and can significantly reduce the retreatment rate, whereas it may cause stronger cerebral blood flow change in the nearby regions and a worse prognosis $[6,47]$. On the other side, patients who have received coiling can benefit from minimally invasive surgery and faster recovery [23].

Several meta-analyses that compared the effectiveness of clipping and coiling have been published. They either only included randomized controlled trials (RCTs) [29, 45] or were based on evidence from RCTs and observational studies [14, 31]. Since RCTs have a high requirement on the eligibility of patients, the generalization of results is questionable [10]. For meta-analysis based on RCTs and observational studies, the reliability of cross-sectional and case-control studies is limited, and the combination of these two types of studies may reduce the internal validity of conclusions. Considering both internal and external validity, this systematic review aims to assess the effectiveness and safety of clipping compared with coiling based on high-quality evidence from both RCTs and prospective cohort studies, and to make a supplementary suggestion on the treatment of aneurysmal SAH patients.

\section{Methods}

\section{Search strategy}

A systematic search of Pubmed, Web of Science, EMBASE, Cochrane Library, the China National Knowledge Infrastructure (CNKI), Wanfang Data, and Sinomed was performed on August 5, 2021. The latter three are Chinese databases. The search strategies were presented in Supplemental Table 1. No restriction was set on the publication date. All references of included studies were also scanned to identify additional relevant articles.

\section{Selection criteria}

The selection process was undertaken by two reviewers independently, and any discrepancy was resolved by discussion. Studies were included if they met the following criteria: (1) RCTs and prospective cohort studies that compared clipping versus coiling in all age groups of aneurysmal SAH patients; (2) studies that reported at least one of the interested effectiveness or safety outcomes of patients at discharge or 1-year follow-up in the two groups. The effectiveness measures included poor outcome rate, mortality, and the rate of complete aneurysmal occlusion. Particularly, poor outcome was defined as death or dependence in daily activities (modified Rankin scale (mRS) with a score of 3-6 or Glasgow Outcome Scale (GOS) with a score of 1-3). The safety outcomes included the rate of rebleeding, ischemic cerebral infarction, vasospasm, and shunt-dependent hydrocephalus.

The exclusion criteria were as follows: (1) RCTs that did not report randomization methods; (2) prospective cohort studies with a substantial imbalance of preoperative characteristics or absence of baseline information; (3) SAH from trauma or infected aneurysms; (4) studies that did not present enough information for us to extract or calculate the absolute number of clinical events; (5) case reports, editorials, conference abstracts, comments, letters, and reviews. If the same data were used in more than one paper, the paper with the largest number of participants would be included.

\section{Data extraction}

The following data were independently extracted by two reviewers using Microsoft Excel 2016, and any disagreement was discussed: (1) Study characteristics: journal, first author and his/her institution, publication year, study period, study setting, and study design. (2) Participants' characteristics: study eligibility criteria, the age range, sex distribution, preoperative grade (including the World Federation of Neurosurgical Surgeons scale (WFNS), Hunt and Hess scales $(\mathrm{H} \& \mathrm{H})$, and Fisher grade), aneurysm location, and aneurysm size of patients. (3) The number of patients treated with clipping or coiling, and outcomes of interest.

\section{Quality assessment}

The methodological quality of RCTs was assessed by the Cochrane Risk of Bias Tool [19], which contains 7 domains: random sequence generation, allocation concealment, blinding of participants and personnel, blinding of outcome assessment, incomplete outcome data, selective reporting, and other biases. For other biases, the baseline characteristic balance between two groups, mainly including preoperative 


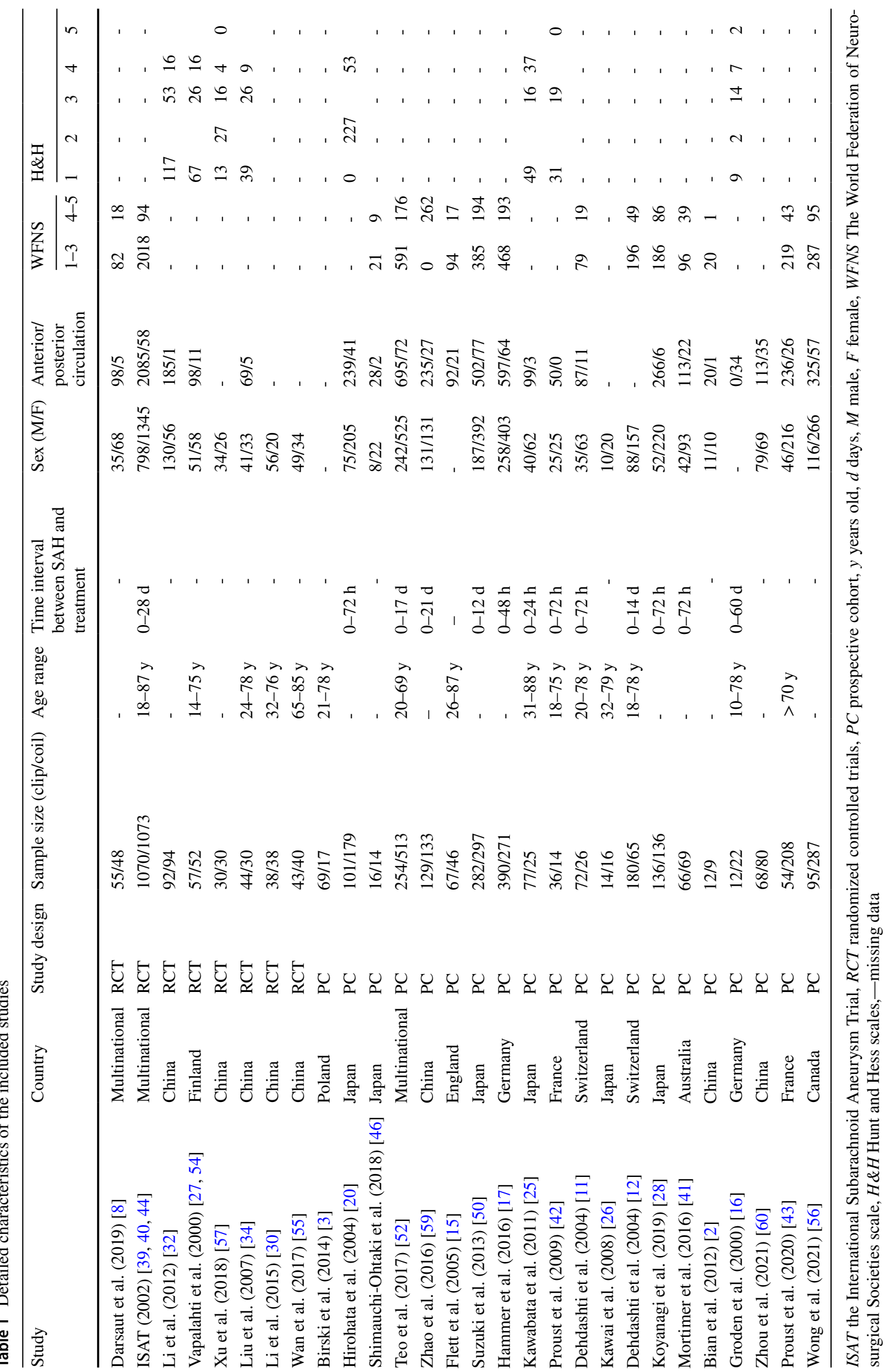


grades, age, and the time interval between $\mathrm{SAH}$ and treatment were assessed [49]. Each domain was scored as high, unclear, or low risk of bias.

The Newcastle-Ottawa scale was used to evaluate the quality of prospective cohort studies based on the selection bias, comparability of the exposed and unexposed cohorts, and outcome assessment of the studies [58]. The maximum score on the scale is 9 which indicates the highest quality.

Two reviewers assessed the quality of the selected studies separately using Review Manager 5.3 (Nordic Cochrane Centre, Cochrane Collaboration, Copenhagen, Denmark) and Microsoft Excel 2016. Any discrepancy was resolved by discussion.

\section{Statistical analysis}

The relative risk (RR, clipping versus coiling) and 95\% confidence interval (CI) of each study were estimated, and the results were presented in forest plots using Review Manager 5.3. For data synthesis, the $I^{2}$ statistic, which indicates the proportion of total variation attributable to the variation between studies, was estimated to assess heterogeneity [19]. After that, the Mantel-Haenszel method was used to pool the data $[13,36]$. The random-effect model would be used if $I^{2}>50 \%$, which demonstrated a high level of heterogeneity. Otherwise, the fixed-effect model would be chosen.

Besides, if the outcomes of patients with specific characteristics were reported, subgroup analyses would be performed to examine which treatment was more suitable for these patients. A funnel plot would also be presented to examine the potential publication bias if more than 10 studies within the same comparison were included [19]. All the findings were reported based on the PRISMA Checklist [38].

\section{Results}

\section{Results of the search}

The literature search identified 5011 articles. Two articles were also found after screening the reference of the included studies. After the removal of duplicates, 3844 studies were screened by titles and abstracts, and 3609 of them were excluded. A total of 235 full-text articles were retrieved, and 204 of them were excluded. Among them, the most common exclusion reason was that RCTs did not report randomization methods or prospective cohort studies did not report baseline information. Eventually, 31 articles were included in this meta-analysis. Among them, 27 articles were written in English, while others were in Chinese. The detailed process of selection and the reasons for exclusion are shown in Fig. 1.

Three articles reported the short-term or 1-year followup outcome from the International Subarachnoid Aneurysm
Trial (ISAT) study [39, 40, 44], and an RCT conducted by Kuopio University Hospital also published two related articles [27, 54]. Other 26 articles described the results from 6 RCTs and 20 prospective cohort studies respectively. As a result, we included 28 independent studies. These studies enrolled 7391 patients in total, with 3559 patients who went through clipping and 3832 patients who received coiling. The median sample size was 111 patients (range, 21-2143 patients), and the age range of enrolled patients was 10 to 88 years old. The median proportion of patients whose aneurysms were located in the anterior circulation was $90.20 \%$ (range, 0.00-100.0\%), and the median proportion of patients with the WFNS classification of $1-3$ was $77.05 \%$ (range, 0.00\%-95.55\%).

Fourteen studies were conducted in Asia, 10 in Europe, and 1 in Australia, while the other 3 studies were multinational. A detailed description of the included studies is shown in Table 1.

\section{The methodological quality of the included studies}

Cochrane Risk of Bias Tool was applied to assess the methodological quality of the RCTs. In all, among the 8 RCTs included, 4 studies clearly described the practice of allocation concealment $[8,27,32,39,40,44,54]$, and 6 studies did not have any loss to follow-up and thus reported all outcome data $[27,30,32,39,40,44,54,55,57]$. In terms of blinding, it is impossible to blind the surgeons, patients, or caregivers given the consideration of ethical and technical issues. However, it has been found that the un-blindness would introduce low bias since both clipping and coiling are standard treatment methods for SAH. The blinding of outcome assessment is feasible, but it was reported in only 1 study [32]. Two studies published the protocol [8, 39, 40, 44], and the reporting bias of the remaining studies was unclear. Besides, 5 studies did not report the baseline characteristics of patients thoroughly $[27,30,34,54,55,57]$. The results of the methodological quality of RCTs are shown in Fig. 2 and Supplemental Fig. 1.

The overall methodological quality of cohort studies included was relatively high, as $70.00 \%$ of them earned $\geq 8$ scores. The representativeness of the cohort was low in 5 studies because they did not include consecutive or random samples $[2,16,28,52,60]$. Seven studies did not state clearly how they assessed the outcomes $[3,12,16,25,46$, $56,60]$. The methodological scores of each cohort are presented in Table 2.

\section{Effectiveness outcome}

Eight studies with a total of 2167 participants reported the poor outcome at discharge $[3,8,20,43,46,52,56,59]$. The result indicated that the risk of poor outcome for patients 


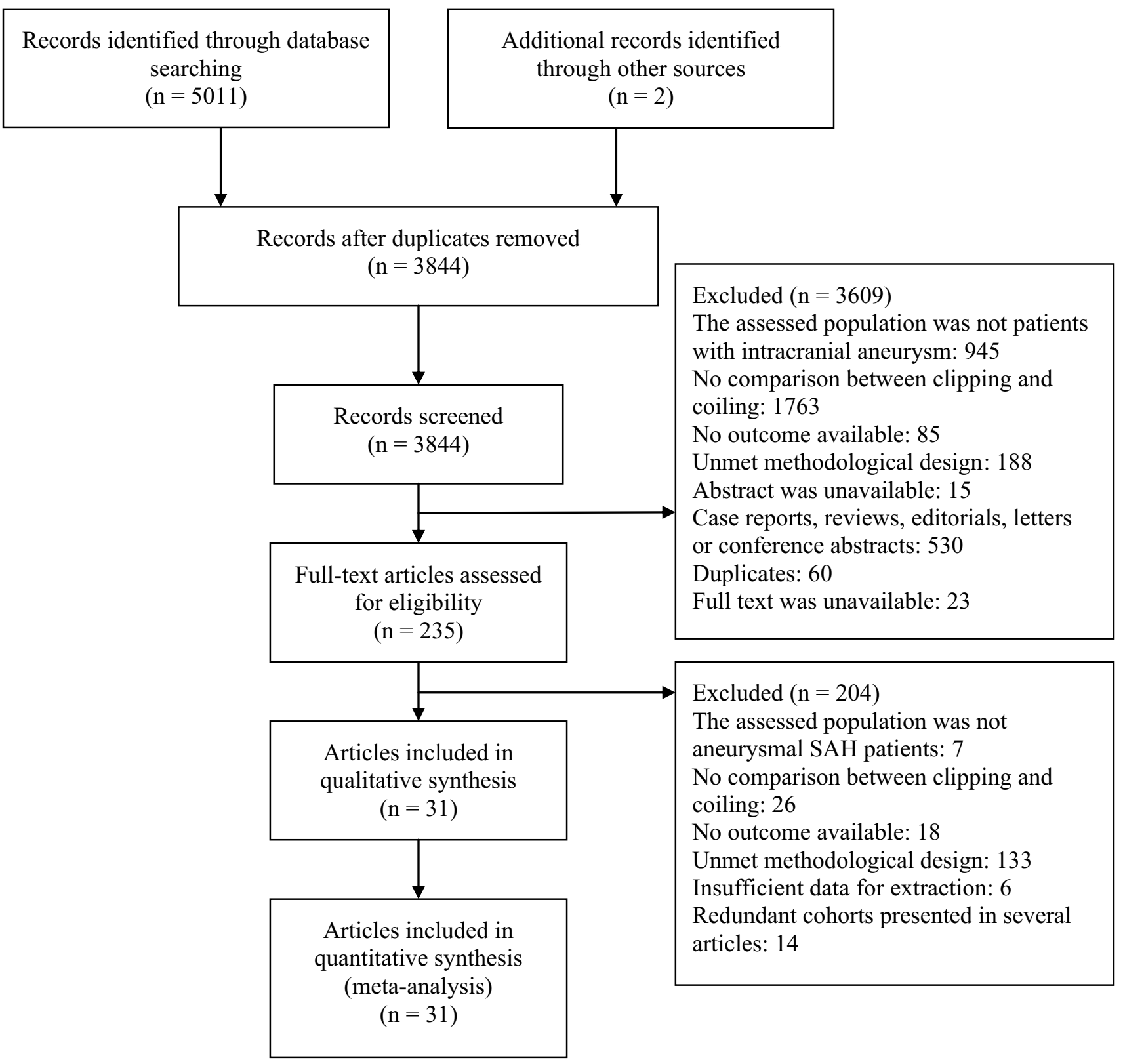

Fig. 1 Flow chart of the selection procedure. SAH subarachnoid hemorrhage

who went through clipping was 1.22 times higher compared with patients who accepted coiling (RR: 1.22, 95\% CI: $1.00-1.47, P=0.04$, Supplemental Fig. 2). Nine studies reported the 1-year outcome of 4050 participants [8, 15, 27, $32,40,43,50,56,59]$, and results showed that clipping was associated with a $27 \%$ greater risk of poor outcome compared with coiling (RR:1.27, 95\% CI: 1.16-1.39, $P<0.001$, Fig. 3).

Six studies reported mortality at discharge $[3,8,20,46$, $56,59]$. The pooled result of 1138 patients showed that the mortality did not differ significantly between the two treatment groups at discharge (RR: 0.94, 95\% CI: 0.69-1.28,
$P=0.69$, Supplemental Fig. 3). No significant difference was found for 1-year mortality based on ten studies (RR: 1.07, 95\% CI: 0.91-1.26, $P=0.44$, Supplemental Fig. 4) [8, 15, 17, 27, 32, 40, 43, 56, 57, 59].

Four studies evaluated complete aneurysmal occlusion in 894 participants at discharge and found that clipping was superior to coiling (RR: $1.21,95 \% \mathrm{CI}: 1.15-1.28, P<0.001$, Supplemental Fig. 5) [17, 34, 42, 54]. At 1-year follow-up, clipping could increase the incidence of complete aneurysmal occlusion by $33 \%$ compared to coiling (RR: $1.33,95 \%$ CI: $1.19-1.48, P<0.001$, Supplemental Fig. 6) $[8,15,27$, $32,57]$. 


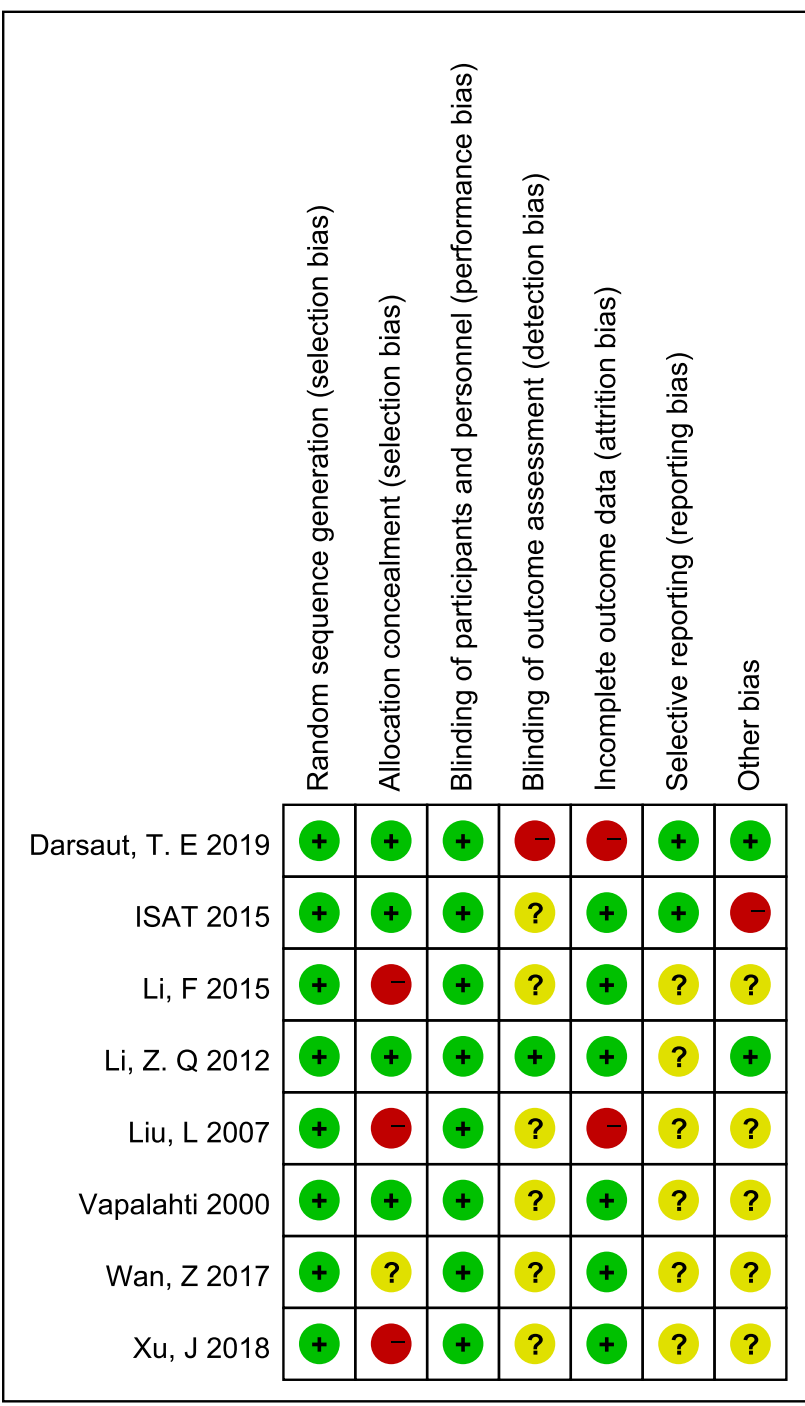

Fig. 2 The detailed methodological quality of included RCTs. ISAT the International Subarachnoid Aneurysm Trial

\section{Safety outcome}

Eight studies with 1868 patients reported the rebleeding rate at discharge [8, 17, 20, 25, 42, 43, 59, 60]. Consequently, clipping was associated with an approximately $48 \%$ decrease in the risk of rebleeding compared to coiling (RR: 0.52, 95\% CI: 0.29-0.94, $P=0.03$, Supplemental Fig. 7). But this advantage was no longer held at 1-year follow-up (RR: 0.56, 95\% CI: 0.22-1.40, $P=0.21$, Supplemental Fig. 8) according to the pooled analysis from 5 studies $[15,17,32,40,56]$.

Nine studies assessed ischemic cerebral infarction at discharge including 2076 participants [11, 17, 20, 26, 30, 46, 50, $57,59]$ and showed no significant effect difference between the two groups (RR: $1.09,95 \%$ CI: 0.59-2.03, $P=0.78$, Supplemental Fig. 9). Four studies reported a 1-year follow-up outcome $[8,17,32,56]$, and no significant difference was found (RR: 1.15, 95\% CI: 0.54-2.44, $P=0.72$, Supplemental Fig. 10).

In terms of other complications, 8 studies reported shuntdependent hydrocephalus at discharge, and the pooled analysis showed no significant difference between the two groups (RR: 1.06, 95\% CI: 0.68-1.67, $P=0.79$, Supplemental Fig. 11) [8, 12, 28, 30, 41, 46, 57, 59]. Furthermore, the pooled summary of 12 studies showed a $45 \%$ increase in the risk of vasospasm at discharge if patients received clipping (RR: $1.45,95 \%$ CI: $1.23-1.71, P<0.001$, Supplemental Fig. 12) $[2,8,11,16,20,41,46,50,55,57,59,60]$.

The effectiveness and safety outcomes of the two treatment arms are summarized in Table 3.

\section{Subgroup analyses}

Several studies reported the 1-year poor outcome of subgroups (Supplemental Fig. 13) [15, 27, 39, 40, 43]. It was suggested that, among patients with a poor neurological condition at admission (WFNS of 4-6), there was no statistically significant difference between clipping and coiling groups (RR: $1.02,95 \%$ CI: $0.82-1.27, P=0.84$ ). Also, the outcome was not significantly different between the two treatment groups in patients with the anterior cerebral artery, anterior communicating artery (ACA-AComA) (RR: 1.12, 95\% CI: $0.92-1.37, P=0.26$ ), or middle cerebral artery (MCA) aneurysms (RR: 0.98 , 95\% CI: 0.69-1.40, $P=0.92$ ). However, coiling yielded a better outcome for patients with the internal carotid artery (ICA) (RR: 1.76, 95\% CI: 1.37-2.25, $P<0.001$ ) or posterior circulation artery (PCA) aneurysms (RR: $2.41,95 \%$ CI: $1.08-5.37, P=0.03$ ). The results of the subgroup analyses are summarized in Table 4.

\section{Publication bias}

Only the comparison of the vasospasm rate included more than 10 studies, and the funnel plot implied the existence of publication bias (Fig. 4).

\section{Discussion}

In all, according to our meta-analysis, clipping had advantages in occluding aneurysms more completely and reducing the risk of rebleeding. In comparison, coiling could lead to a risk reduction for poor outcome and vasospasm. The mortality, ischemic cerebral infarction rate, and shunt-dependent hydrocephalus rate did not differ significantly between the two groups. The updated Cochrane systematic review which only included 4 RCTs demonstrated a better outcome for coiling patients despite its higher rebleeding rate, which is in line with our results [33]. However, since its results were largely influenced by ISAT, the evidence of the Cochrane 


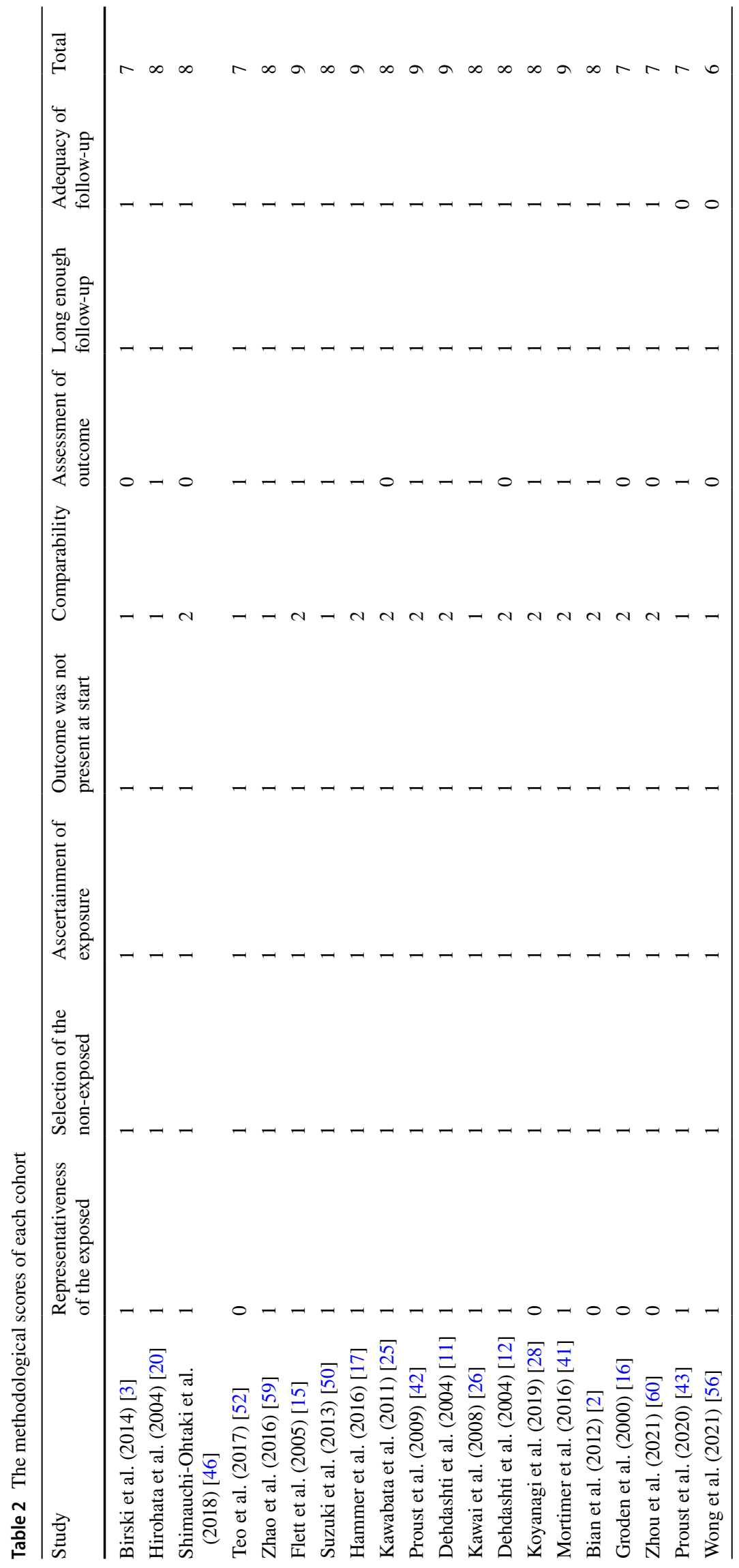




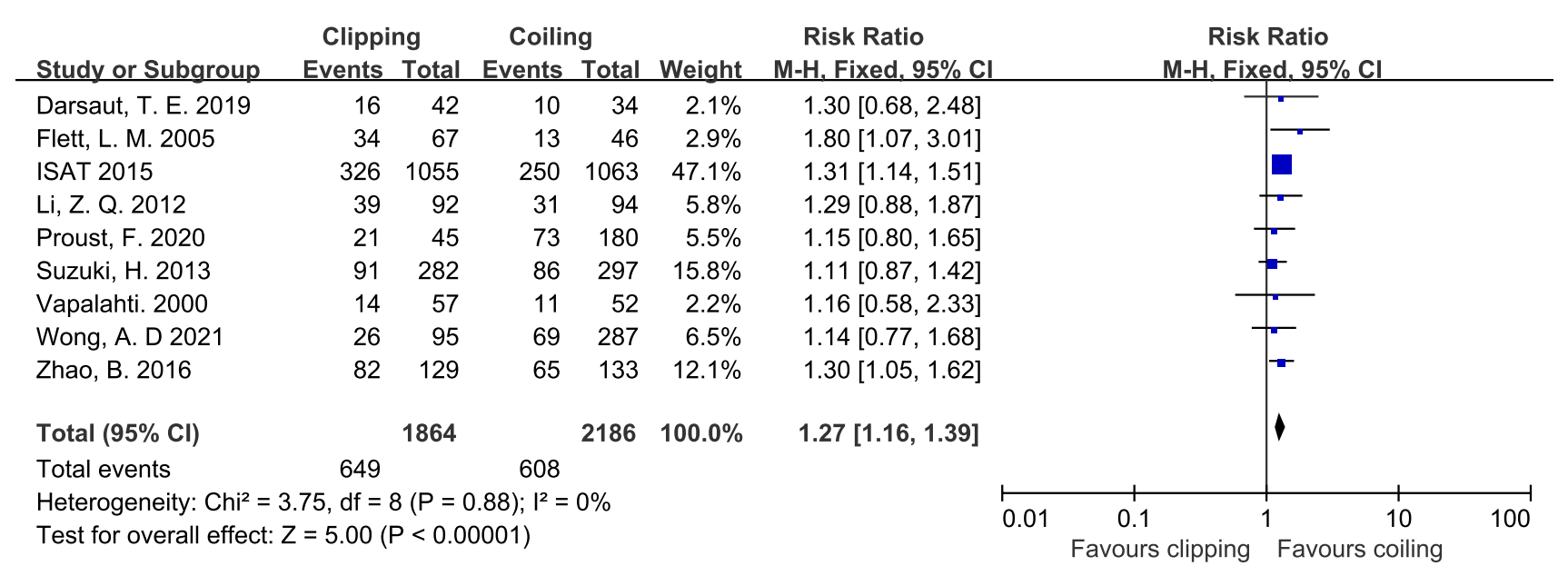

Fig. 3 Effect of clipping versus coiling on the poor outcome rate at 1-year follow-up. ISAT the International Subarachnoid Aneurysm Trial, CI confidence interval, M-H Mantel-Haenszel method

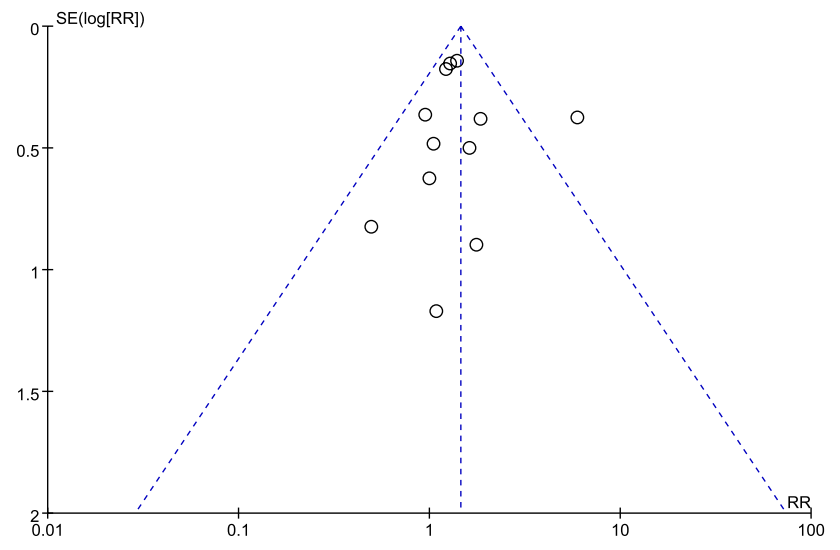

Fig. 4 Publication bias of included studies on the vasospasm rate at discharge. SE standard error, RR relative risk

review could only be extrapolated to patients with a better health status or aneurysms located in the anterior circulation. The meta-analysis conducted by Li et al. included 4 RCTs, 7 prospective cohort studies, 14 retrospective cohort studies, and 2 ambispective cohort studies [31]. It also found that clipping reduced the incidence of rebleeding, which could be explained by its better complete occlusion rate, and there was no significant difference for mortality. Vasospasm was also more common among patients treated with clipping. Besides, a nationwide database-based meta-analysis also found that in-hospital mortality was not significantly different between matched clipping and coiling groups [22].

According to the European Stroke Organization (ESO) Guidelines, the neurological condition of SAH patients when they were admitted has a strong influence on their prognosis. This condition is generally assessed by several grading instruments, such as WFNS, $\mathrm{H} \& \mathrm{H}$, and Glasgow Coma Scale [49]. This enables us to undertake subgroup analyses to test whether the effects of the two treatments were similar for patients with different preoperative grades. The results demonstrated that among patients with a poor neurological condition at admission, treatment modality was not a significant prognostic factor. Comparable conclusions have also been drawn by Li et al. [31]. Besides, our subgroup analyses also discovered that the prognosis was not significantly affected by treatments in patients with ACA, AComA, or MCA aneurysms. ESO Guidelines also recommended that patients with MCA should preferably be treated by clipping [49]. However, since each subgroup analysis only included 2-3 studies, the evidence was relatively weak. Further RCTs and prospective cohort studies are needed to investigate the treatment effectiveness for patients with different characteristics.

Currently, coiling has become the dominant treatment method in many countries, such as the USA, western Europe, and China due to the ISAT trial [1, 4, 48]. Also, as craniotomy is more difficult to operate than minimally invasive surgery, the spread of coiling treatment is more rapid than clipping. However, our subgroup analyses suggested that the decision on treatment selection should be made based on the clinical characteristics of SAH patients. Besides, as the medical costs of coiling are generally higher than clipping [37, 51], "coiling mainly" policy may impose an additional or unnecessary economic burden on both society and patients. Therefore, in consideration of both clinical benefits and health expenses, the preference for coiling should be changed and clinical guidelines should be considered. So far, both ESO and the American Heart Association/American Stroke Association have published guidelines for the management of patients with ruptured and unruptured IA $[49,53]$. Countries can use and amend them based on the health needs of the local population and the level of medical technology. 
Table 3 The effectiveness and safety outcomes of the two treatments

\begin{tabular}{|c|c|c|c|c|c|c|c|}
\hline Category & Indicator & $N$ & $\mathrm{RR}$ & $95 \% \mathrm{CI}$ & Favors clipping & Favors coiling & $\begin{array}{l}\text { No signifi- } \\
\text { cant differ- } \\
\text { ence }\end{array}$ \\
\hline \multirow[t]{6}{*}{ Effectiveness } & Poor outcome-discharge & 8 & $1.22 *$ & $1.00-1.47$ & & $\sqrt{ }$ & \multirow{6}{*}{$\begin{array}{l}\sqrt{ } \\
\sqrt{ }\end{array}$} \\
\hline & Poor outcome -1 year & 9 & $1.27 *$ & $1.16-1.39$ & & $\sqrt{ }$ & \\
\hline & Mortality_discharge & 6 & 0.94 & $0.69-1.28$ & & & \\
\hline & Mortality -1 year & 10 & 1.07 & $0.91-1.26$ & & & \\
\hline & Complete aneurysmal occlusion-discharge & 4 & $1.21 *$ & $1.15-1.28$ & $\sqrt{ }$ & & \\
\hline & Complete aneurysmal occlusion -1 year & 5 & $1.33 *$ & $1.19-1.48$ & $\sqrt{ }$ & & \\
\hline \multirow[t]{6}{*}{ Safety } & Rebleeding-discharge & 8 & $0.52 *$ & $0.29-0.94$ & $\sqrt{ }$ & & \multirow{6}{*}{$\begin{array}{l}\sqrt{ } \\
\sqrt{ } \\
\sqrt{ } \\
\sqrt{ }\end{array}$} \\
\hline & Rebleeding-1 year & 5 & 0.56 & $0.22-1.40$ & & & \\
\hline & Ischemic cerebral infarction-discharge & 9 & 1.09 & $0.59-2.03$ & & & \\
\hline & Ischemic cerebral infarction-1 year & 4 & 1.15 & $0.54-2.44$ & & & \\
\hline & Shunt-dependent hydrocephalus_-discharge & 8 & 1.06 & $0.68-1.67$ & & & \\
\hline & Vasospasm—discharge & 12 & $1.45^{*}$ & $1.23-1.71$ & & $\sqrt{ }$ & \\
\hline
\end{tabular}

$N$ num of studies, $R R$ relative risk, $C I$ confidence interval

${ }^{*} p<0.05$

Table 4 The results of subgroup analyses

\begin{tabular}{lllllcc}
\hline Indicator & Subgroup & $N$ & RR & $95 \%$ CI & $\begin{array}{c}\text { Favors clipping } \\
\text { Favors coiling }\end{array}$ & $\begin{array}{c}\text { No signifi- } \\
\text { cant differ- } \\
\text { ence }\end{array}$ \\
\hline $\begin{array}{l}\text { Poor out- } \\
\text { come-1 year }\end{array}$ & Fisher grade of $0-2$ & 2 & $1.63^{*}$ & $1.06-2.48$ & $\sqrt{ }$ \\
& Fisher grade of 3-4 & 2 & $1.26^{*}$ & $1.09-1.45$ & $\sqrt{ }$ \\
& WFNS of 1-3 & 3 & $1.40^{*}$ & $1.21-1.62$ & $\sqrt{ }$ \\
& WFNS of 4-6 & 3 & 1.02 & $0.82-1.27$ & $\sqrt{ }$ \\
& ACA-AComA & 2 & 1.12 & $0.92-1.37$ & $\sqrt{ }$ \\
& MCA & 2 & 0.98 & $0.69-1.40$ & $\sqrt{ }$ \\
& ICA & 2 & $1.76^{*}$ & $1.37-2.25$ & $\sqrt{ }$ \\
& PCA & 2 & $2.41^{*}$ & $1.08-5.37$ & \\
\hline
\end{tabular}

$N$ num of studies, $R R$ relative risk, $C I$ confidence interval, WFNS the World Federation of Neurosurgical Surgeons scale, $A C A$ anterior cerebral artery, AComA anterior communicating artery, $M C A$ middle cerebral artery, ICA internal carotid artery, $P C A$ posterior circulation artery ${ }^{*} p<0.05$

This review combined the evidence generated by RCTs and prospective cohort studies. Compared to the current RCTbased systematic review [33], we included other four RCTs that were conducted in China and published in Chinese journals. In addition to this, the recently published interim analysis of the ISAT-2 trial, which considered patients that were not included in the ISAT trial [7], has been added. This evidence may be helpful to improve the representativeness of included patients. Moreover, the overall methodological quality of the eligible cohort studies was high, considering both the representativeness and baseline comparability. Therefore, the results of this review are pragmatic in routine clinical practice.
This study has the following limitations: First, only two RCTs published the research protocols, and reporting bias of other RCTs remains unclear. Besides, $62.50 \%$ of included RCTs did not provide enough information on baseline characteristics of patients, and $40.00 \%$ of cohort studies did not reach a complete balance in baseline characteristics between clipping and coiling cohorts. The uncertainty and imbalance between the two treatment groups could introduce confounder bias. Second, most of the studies were performed in Europe, Eastern Asia, and North America. The results may be unrepresentative to other regions of the world. 


\section{Conclusion}

In summary, each treatment modality has its own pros and cons. Coiling yielded a better clinical outcome at shortand long-term follow-up, but the rebleeding risk was lower if patients received clipping. Besides, for patients with a poor neurological condition at admission, there was no statistically significant outcome difference between the two treatments. Therefore, comprehensive considerations should be given on the selection of treatment for SAH patients, considering both patients' preference and their preoperative condition.

Supplementary Information The online version contains supplementary material available at https://doi.org/10.1007/s10143-021-01704-0.

Author contribution $\mathrm{JH}$ and $\mathrm{WZ}$ conceived and planned the study. WZ did the literature retrieve. WZ, JL, and AX applied selection criteria, extracted data, and evaluated study quality. WZ synthesized the data and wrote the initial draft of the manuscript. JH, XL, JDP critically reviewed and revised the draft. All authors contributed to data result interpretation.

Availability of data and material Not applicable.

Code availability Not applicable.

\section{Declarations}

Ethics approval Not applicable.

Consent to participate Not applicable.

Consent for publication Not applicable.

Competing interests The authors declare no competing interests.

Open Access This article is licensed under a Creative Commons Attribution 4.0 International License, which permits use, sharing, adaptation, distribution and reproduction in any medium or format, as long as you give appropriate credit to the original author(s) and the source, provide a link to the Creative Commons licence, and indicate if changes were made. The images or other third party material in this article are included in the article's Creative Commons licence, unless indicated otherwise in a credit line to the material. If material is not included in the article's Creative Commons licence and your intended use is not permitted by statutory regulation or exceeds the permitted use, you will need to obtain permission directly from the copyright holder. To view a copy of this licence, visit http://creativecommons.org/licenses/by/4.0/.

\section{References}

1. Andaluz N, Zuccarello M (2008) Recent trends in the treatment of cerebral aneurysms: analysis of a nationwide inpatient database. J Neurosurg 108(6):1163-1169. https://doi.org/10.3171/jns/2008/ $108 / 6 / 1163$
2. Bian LH, Liu LP, Wang WJ et al (2012) Continual transcranial Doppler in the monitoring of hemodynamic change following aneurysmal subarachnoid hemorrhage. CNS Neurosci Ther 18(8):631-635. https://doi.org/10.1111/j.1755-5949.2012.00327.x

3. Birski M, Walesa C, Gaca W, Paczkowski D, Birska J, Harat A (2014) Clipping versus coiling for intracranial aneurysms. Neurol Neurochir Pol 48(2):122-129. https://doi.org/10.1016/j.pjnns. 2014.03.002

4. Bradac O, Hide S, Mendelow DA, Benes V (2012) Aneurysm treatment in Europe 2010: an internet survey. Acta Neurochir (Wien) 154(6):971-978. https://doi.org/10.1007/ s00701-012-1340-2

5. Brisman JL, Song JK, Newell DW (2006) Cerebral aneurysms. N Engl J Med 355(9):928-939. https://doi.org/10.1056/NEJMr a052760

6. Campi A, Ramzi N, Molyneux AJ et al (2007) Retreatment of ruptured cerebral aneurysms in patients randomized by coiling or clipping in the International Subarachnoid Aneurysm Trial (ISAT). Stroke 38(5):1538-1544. https://doi.org/10.1161/strok eaha.106.466987

7. Darsaut TE, Jack AS, Kerr RS, Raymond J (2013) International Subarachnoid Aneurysm Trial-ISAT part II: study protocol for a randomized controlled trial. Trials 14:156. https://doi.org/10. 1186/1745-6215-14-156

8. Darsaut TE, Roy D, Weill A et al (2019) A randomized trial of endovascular versus surgical management of ruptured intracranial aneurysm: interim results from ISAT2. Neurochirurgie. https:// doi.org/10.1016/j.neuchi.2019.05.008

9. de Rooij NK, Linn FH, van der Plas JA, Algra A, Rinkel GJ (2007) Incidence of subarachnoid haemorrhage: a systematic review with emphasis on region, age, gender and time trends. J Neurol Neurosurg Psychiatry 78(12):1365-1372. https://doi.org/10.1136/jnnp. 2007.117655

10. Deaton A, Cartwright N (2018) Understanding and misunderstanding randomized controlled trials. Soc Sci Med 210:2-21. https://doi.org/10.1016/j.socscimed.2017.12.005

11. Dehdashti AR, Mermillod B, Rufenacht DA, Reverdin A, de Triboleta N (2004) Does treatment modality of intracranial ruptured aneurysms influence the incidence of cerebral vasospasm and clinical outcome? Cerebrovasc Dis 17(1):53-60. https://doi.org/ 10.1159/000073898

12. Dehdashti AR, Rilliet B, Rufenacht DA, de Tribolet N (2004) Shunt-dependent hydrocephalus after rupture of intracranial aneurysms: a prospective study of the influence of treatment modality. J Neurosurg 101(3):402-407. https://doi.org/10.3171/ jns.2004.101.3.0402

13. DerSimonian R, Laird N (1986) Meta-analysis in clinical trials. Control Clin Trials 7(3):177-188. https://doi.org/10.1016/ 0197-2456(86)90046-2

14. Falk Delgado A, Andersson T, Falk Delgado A (2017) Clinical outcome after surgical clipping or endovascular coiling for cerebral aneurysms: a pragmatic meta-analysis of randomized and non-randomized trials with short- and long-term follow-up. J Neurointerv Surg 9(3):264-277. https://doi.org/10.1136/neuri ntsurg-2016-012292

15. Flett LM, Chandler CS, Giddings D, Gholkar A (2005) Aneurysmal subarachnoid hemorrhage: management strategies and clinical outcomes in a regional neuroscience center. AJNR Am J Neuroradiol 26(2):367-372

16. Groden C, Regelsberger J, Neumaier-Probst E, Grzyska U, Herrmann HD, Zeumer H (2000) Operative or endovascular treatment of ruptured intracranial vertebral artery aneurysms? Neuroradiology 42(9):685-691. https://doi.org/10.1007/s0023 40000378 
17. Hammer A, Steiner A, Kerry G et al (2016) Efficacy and safety of treatment of ruptured intracranial aneurysms. World Neurosurg 98:780-789. https://doi.org/10.1016/j.wneu.2016.07.013

18. Heros RC (1989) Acute hydrocephalus after subarachnoid hemorrhage. Stroke 20(6):715-717. https://doi.org/10.1161/01.str.20.6. 715

19. Higgins JP, Green S (2011) Cochrane handbook for systematic reviews of interventions version 5.1.0 (updated March 2011). The Cochrane Collaboration, London

20. Hirohata M, Abe T, Fujimura N, Takeuchi Y, Morimitsu H, Shigemori M (2004) Clinical outcomes of coil embolization for acutely ruptured aneurysm - comparison with results of neck clipping when coil embolization is considered the first option. Interv Neuroradiol 10:49-53. https://doi.org/10.1177/15910199040100s 210

21. Hop JW, Rinkel GJ, Algra A, van Gijn J (1997) Case-fatality rates and functional outcome after subarachnoid hemorrhage: a systematic review. Stroke 28(3):660-664. https://doi.org/10.1161/01.str. 28.3.660

22. Ikawa F, Michihata N, Matsushige T et al (2020) In-hospital mortality and poor outcome after surgical clipping and endovascular coiling for aneurysmal subarachnoid hemorrhage using nationwide databases: a systematic review and meta-analysis. Neurosurg Rev 43(2):655-667. https://doi.org/10.1007/s10143-019-01096-2

23. Johnston SC, Dudley RA, Gress DR, Ono L (1999) Surgical and endovascular treatment of unruptured cerebral aneurysms at university hospitals. Neurology 52(9):1799-1805. https://doi.org/10. 1212/wnl.52.9.1799

24. Kassell NF, Torner JC (1983) Aneurysmal rebleeding: a preliminary report from the Cooperative Aneurysm Study. Neurosurgery 13(5):479-481. https://doi.org/10.1227/00006123-19831 1000-00001

25. Kawabata Y, Horikawa F, Ueno Y, Sawada M, Isaka F, Miyake $\mathrm{H}$ (2011) Clinical predictors of delayed cerebral ischemia after subarachnoid hemorrhage: first experience with coil embolization in the management of ruptured cerebral aneurysms. J Neurointerv Surg 3(4):344-347. https://doi.org/10.1136/jnis.2010.004077

26. Kawai N, Nakamura T, Tamiya T, Nagao S (2008) Regional cerebral blood flow and oxygen metabolism in aneurysmal subarachnoid hemorrhage: positron emission tomography evaluation of clipping versus coiling. Cerebral Hemorrhage Acta Neurochir Suppl 105:211-215. https://doi.org/10.1007/978-3-211-09469-3_ 40

27. Koivisto T, Vanninen R, Hurskainen H, Saari T, Hernesniemi J, Vapalahti M (2000) Outcomes of early endovascular versus surgical treatment of ruptured cerebral aneurysms. A prospective randomized study Stroke 31(10):2369-2377

28. Koyanagi M, Fukuda H, Saiki M et al (2019) Effect of choice of treatment modality on the incidence of shunt-dependent hydrocephalus after aneurysmal subarachnoid hemorrhage. J Neurosurg 130(3):949-955. https://doi.org/10.3171/2017.9.Jns171806

29. Lanzino G, Murad MH, d'Urso PI, Rabinstein AA (2013) Coil embolization versus clipping for ruptured intracranial aneurysms: a meta-analysis of prospective controlled published studies. AJNR Am J Neuroradiol 34(9):1764-1768. https://doi.org/10.3174/ajnr. A3515

30. Li F (2015) A preliminary review of the choice of clinical treatment plan and its effect in patients with ruptured cerebral aneurysm. Journal of Frontiers of Medicine 5(32):109-110

31. Li H, Pan R, Wang H et al (2013) Clipping versus coiling for ruptured intracranial aneurysms: a systematic review and metaanalysis. Stroke 44(1):29-37. https://doi.org/10.1161/strokeaha. 112.663559

32. Li ZQ, Wang QH, Chen G, Quan Z (2012) Outcomes of endovascular coiling versus surgical clipping in the treatment of ruptured intracranial aneurysms. J Int Med Res 40(6):2145-2151. https:// doi.org/10.1177/030006051204000612

33. Lindgren A, Vergouwen MDI, van der Schaaf I, et al. (2018) Endovascular coiling versus neurosurgical clipping for people with aneurysmal subarachnoid haemorrhage. Cochrane Database Syst Rev 8(8):CD003085-CD003085. https://doi.org/10.1002/14651 858.CD003085.pub3

34. Liu L, Liu Y, Yu 1, Shi L, Zhang Y (2007) Early surgical clipping versus endovascular embolization of ruptured intracranial aneurysms: a single center prospective study. Chin J Cerebrovasc Dis(Electr Vers) 1(3):129-133.

35. Maher M, Schweizer TA, Macdonald RL (2020) Treatment of spontaneous subarachnoid hemorrhage: guidelines and gaps. Stroke 51(4):1326-1332. https://doi.org/10.1161/strokeaha.119. 025997

36. Mantel N, Haenszel W (1959) Statistical aspects of the analysis of data from retrospective studies of disease. J Natl Cancer Inst 22(4):719-748

37. Maud A, Lakshminarayan K, Suri MF, Vazquez G, Lanzino G, Qureshi AI (2009) Cost-effectiveness analysis of endovascular versus neurosurgical treatment for ruptured intracranial aneurysms in the United States. J Neurosurg 110(5):880-886. https://doi.org/ 10.3171/2008.8.JNS0858

38. Moher D, Liberati A, Tetzlaff J, Altman DG (2010) Preferred reporting items for systematic reviews and meta-analyses: the PRISMA statement. Int J Surg 8(5):336-341. https://doi.org/10. 1016/j.ijsu.2010.02.007

39. Molyneux A, Kerr R, Stratton I et al (2002) International Subarachnoid Aneurysm Trial (ISAT) of neurosurgical clipping versus endovascular coiling in 2143 patients with ruptured intracranial aneurysms: a randomised trial. Lancet 360(9342):1267-1274. https://doi.org/10.1016/S0140-6736\%2802\%2911314-6

40. Molyneux AJ, Kerr RS, Yu LM et al (2005) International subarachnoid aneurysm trial (ISAT) of neurosurgical clipping versus endovascular coiling in 2143 patients with ruptured intracranial aneurysms: a randomised comparison of effects on survival, dependency, seizures, rebleeding, subgroups, and aneurysm occlusion. Lancet 366(9488):809-817. https://doi.org/10.1016/s01406736(05)67214-5

41. Mortimer AM, Bradford C, Steinfort B, Faulder K, Assaad N, Harrington T (2016) Short term outcomes following clipping and coiling of ruptured intracranial aneurysms: does some of the benefit of coiling stem from less procedural impact on deranged physiology at presentation? J Neurointerv Surg 8(2):145-151. https://doi.org/10.1136/neurintsurg-2014-011533

42. Proust F, Martinaud O, Gerardin E et al (2009) Quality of life and brain damage after microsurgical clip occlusion or endovascular coil embolization for ruptured anterior communicating artery aneurysms: neuropsychological assessment—clinical article. J Neurosurg 110(1):19-29. https://doi.org/10.3171/2008.3.17432

43. Proust F, Bracard S, Thines L et al (2020) Functional outcome 1 year after aneurysmal subarachnoid hemorrhage due to ruptured intracranial aneurysm in elderly patients. Neurochirurgie 66(1):1-8. https://doi.org/10.1016/j.neuchi.2019.11.002

44. Ryttlefors M, Enblad P, Kerr RSC, Molyneux AJ (2008) International subarachnoid aneurysm trial of neurosurgical clipping versus endovascular coiling: subgroup analysis of 278 elderly patients. Stroke 39(10):2720-2726. https://doi.org/10.1161/ STROKEAHA.107.506030

45. Shao B, Wang JY, Chen Y et al (2019) Clipping versus coiling for ruptured intracranial aneurysms: a meta-analysis of randomized controlled trials. World Neurosurg 127:E353-E365. https://doi. org/10.1016/j.wneu.2019.03.123

46. Shimauchi-Ohtaki H, Tosaka M, Ohtani T et al (2018) Systemic metabolism and energy consumption after microsurgical clipping 
and endovascular coiling for aneurysmal subarachnoid hemorrhage. Acta Neurochir (Wien) 160(2):261-268. https://doi.org/ 10.1007/s00701-017-3400-0

47. Shimizu H, Inoue T, Fujimura M, Saito A, Tominaga T (2011) Cerebral blood flow after surgery for unruptured cerebral aneurysms: effects of surgical manipulation and irrigation fluid. Neurosurgery 69(3):677-688. https://doi.org/10.1227/NEU.0b013e3182 195509

48. Smith GA, Dagostino P, Maltenfort MG, Dumont AS, Ratliff JK (2011) Geographic variation and regional trends in adoption of endovascular techniques for cerebral aneurysms. J Neurosurg 114(6):1768-1777. https://doi.org/10.3171/2011.1.Jns101528

49. Steiner T, Juvela S, Unterberg A et al (2013) European Stroke Organization guidelines for the management of intracranial aneurysms and subarachnoid haemorrhage. Cerebrovasc Dis 35(2):93112. https://doi.org/10.1159/000346087

50. Suzuki H, Taki W (2013) Effect of aneurysm treatment modalities on cerebral vasospasm after aneurysmal subarachnoid hemorrhage. Acta Neurochir Suppl 115:99-105. https://doi.org/10.1007/ 978-3-7091-1192-5_22

51. Tahir MZ, Enam SA, Ali RP, Bhatti A, U1 Haq T (2009) Costeffectiveness of clipping vs coiling of intracranial aneurysms after subarachnoid hemorrhage in a developing country-a prospective study. Surg Neurol 72(4):355-361. https://doi.org/10.1016/j. surneu.2008.11.003

52. Teo M, Guilfoyle MR, Turner C, Kirkpatrick PJ (2017) What factors determine treatment outcome in aneurysmal subarachnoid hemorrhage in the modern era? A post hoc STASH analysis. World Neurosurg 105:270-281. https://doi.org/10.1016/j.wneu. 2017.05.005

53. Thompson BG, Brown RD Jr, Amin-Hanjani S et al (2015) Guidelines for the management of patients with unruptured intracranial aneurysms: a guideline for healthcare professionals from the American Heart Association/American Stroke Association. Stroke 46(8):2368-2400. https://doi.org/10.1161/STR.00000 00000000070

54. Vanninen R, Koivisto T, Saari T, Hernesniemi J, Vapalahti M (1999) Ruptured intracranial aneurysms: acute endovascular treatment with electrolytically detachable coils-a prospective randomized study. Radiology 211(2):325-336. https://doi.org/ 10.1148/radiology.211.2.r99ap06325

55. Wan Z (2017) Effect of intravascular treatment on symptomatic cerebral vasospasm in elderly patients with aneurysmal subarachnoid hemorrhage. Chinese Journal of Practical Nervous Diseases 20(1):56-58

56. Wong AD, Alubankudi R, Jarrett J, Huynh TJ, Dmytriw AA, Pickett GE (2021) Management of ruptured intracranial aneurysms in the post-international subarachnoid aneurysm trial era: a singlecentre prospective series. Can J Neurol Sci:1-8. https://doi.org/ $10.1017 /$ cjn. 2021.45

57. Xu J, Liu B (2018) Safety and clinical efficacy of microsurgical clipping compared with endovascular coiling in treatment of ruptured aneurysm of middle cerebral artery. Safety and clinical efficacy of microsurgical clipping compared with endovascular coiling in treatment of ruptured aneurysm of middle cerebral artery. Journal of Clinical and Experimental Medicine 17(16):1751-1754.

58. Zeng X, Zhang Y, Kwong JSW et al (2015) The methodological quality assessment tools for preclinical and clinical studies, systematic review and meta-analysis, and clinical practice guideline: a systematic review. J Evid Based Med 8(1):2-10. https://doi.org/ 10.1111/jebm.12141

59. Zhao B, Tan X, Yang H et al (2016) Endovascular coiling versus surgical clipping for poor-grade ruptured intracranial aneurysms: postoperative complications and clinical outcome in a multicenter poor-grade aneurysm study. AJNR Am J Neuroradiol 37(5):873878. https://doi.org/10.3174/ajnr.A4649

60. Zhou D, Wei D, Xing W, Li T, Huang Y (2021) Effects of craniotomy clipping and interventional embolization on treatment efficacy, cognitive function and recovery of patients complicated with subarachnoid hemorrhage. Am J Transl Res 13(5):5117-5126

Publisher's Note Springer Nature remains neutral with regard to jurisdictional claims in published maps and institutional affiliations. 